\title{
Solid State Impact Welds Between Dissimilar Metals Utilizing Vaporizing Foil Actuators: A Microstructural Evaluation
}

\author{
Katrina N. Boos, Anupam Vivek, Steven R. Hansen, Bert C. Liu, Glenn S. Daehn \\ Ohio State University, Department of Materials Science and Engineering, Columbus, OH, USA
}

This work aims to study the effect of microstructures of collision welds between various dissimilar metals on the mechanical properties of the weld. In this work, welding between the aluminum-copper, copper-titanium, aluminum-magnesium, titanium-steel, and copper-steel was attempted, and the weld interfaces were examined using optical and electron microscopy. Instrumented peel tests were performed for a qualitative correlation of weld strengths and weld interface microstructure.

Collision welding is traditionally performed using explosives or, less commonly, electromagnetic forces. The benefit of any type of collision welding is the ability to create welds between materials which would not be considered compatible by traditional fusion welding techniques. As a solid state welding process, there is not enough heat to form a heat-affected zone, as discussed by Kore [1]. The weld interface is consequently devoid of undesirable brittle intermetallic compounds. The characteristic morphology of a collision welded interface is wavy, with dissimilar material interlocking observed in many cases. Variations of impact angle, flyer velocity, material properties, and work piece geometry all have an effect on the resulting interface, as discussed by Bahrani et al [2] and Grignon et al [3].

For this work, propulsion was provided by the vaporization of a dogbone-shaped, $0.0762 \mathrm{~mm}$ thick aluminum foil by passing a current through it on the order of $100 \mathrm{kA}$. This tool is known as the vaporizing foil actuator, and was developed by Vivek et al [4]. Upon vaporization, a highly pressurized region is created and used for forcing one work piece into another. One of the work pieces is held stationary (target) while the other (flyer) is launched using the high-pressure region created by vaporization. Flyers had a thickness of $0.5-1.0 \mathrm{~mm}$ and target thicknesses ranged from $0.5-5.0 \mathrm{~mm}$. The flyer was placed directly against an electrically insulated foil, and the ends of the foil were connected to the terminals of a capacitor bank. A steel backing block was placed beneath the foil in order to direct the reaction forces towards the target. The target was separated a distance of 1-3 $\mathrm{mm}$ from the flyer using fiber glass standoffs. This gap in the apparatus allows the flyer enough distance to reach velocities of up to $800 \mathrm{~m} / \mathrm{s}$. Velocities were tracked using a laser-based interferometer. A schematic of the apparatus is shown in Figure 1.

Initial testing of this method with different material combinations was completed with a standard input energy of $7.2 \mathrm{~kJ}$. Flyers and targets were both $76.2 \mathrm{~mm}$ wide and $101.6 \mathrm{~mm}$ long, with a thickness of $0.508 \mathrm{~mm}$. Several tests on thicker steel targets $(4.76 \mathrm{~mm})$ were also performed. Samples were then cross-sectioned and microscopically examined. The specific alloys utilized can be seen in Table 1. A variety of morphologies could be found on the same weld surfaces. Interlocking wavy interfaces were observed for $\mathrm{Cu}-\mathrm{Ti}$ and $\mathrm{Cu}-\mathrm{Fe}$ welds, an example of which is shown in Figure 2. Other combinations of materials, including $\mathrm{Cu}-\mathrm{Al}, \mathrm{Al}-\mathrm{Mg}$, and $\mathrm{Ti}-\mathrm{Fe}$ exhibited features such as non-interlocking waves, voids, intermetallics, and lack of weld altogether.

Peel tests were performed for each weld combination in order to correlate morphology to weld strength. The amount of energy required to peel $\mathrm{Cu}-\mathrm{Ti}$ and $\mathrm{Cu}-\mathrm{Fe}$ was within the range of 4 to $10 \mathrm{~J}$. In contrast, the energy required to separate $\mathrm{Cu}-\mathrm{Al}, \mathrm{Al}-\mathrm{Mg}$, and Ti-Fe welds ranged from 0.01 to $0.2 \mathrm{~J}$. Energy dispersive spectroscopy (EDS) mapping of the fracture surface of an exemplar peel test sample showed significant material exchange. Further work in correlating weld strength and the interlocking nature of the wavy pattern observed at the interface was pursued in the work of Vivek et al [5]. 
Optimization of welding angle and impact velocity was accomplished through systematic alteration of those two variables while keeping all other experimental parameters constant. Collision angles between $8^{\circ}$ and $28^{\circ}$ and impact velocities between $440 \mathrm{~m} / \mathrm{s}$ and $860 \mathrm{~m} / \mathrm{s}$ were investigated. Based on the presence and strength of the wavy interface, a "weldig window" was created by plotting impact velocity against collision angle. A similar set of experiments for the determination of optimal welding parameters could be employed for any material combination. This particular effort is detailed in the work of Vivek et al [5], which is currently under review.

Future work includes the testing of additional material pairings, performing nanohardness traverses across the interfaces to investigate the effect of the weld on the parent material, and additional tests to verify the relationship between interface morphology and mechanical properties of the weld.

References:

[1] Kore, S.D., 2008. Indian Institute of Technology, Bombay.

[2] Bahrani, A.S., Black, T.J., Crossland, B. Proceedings of the Royal Society of London (1967) p. 123-136.

[3] Grignon, F. et al. International Journal of Impact Engineering 30 (2004), p. 1333-1351.

[4] Vivek, A. et al. Journal of Materials Processing Technology 213 (2013), p. 2304-2311.

[5] Vivek, A. et al. Under review for Journal of Materials Processing Technology (2014).

\begin{tabular}{cccccc}
\hline Material & Copper $(\mathrm{Cu})$ & Aluminum $(\mathrm{Al})$ & Magnesium $(\mathrm{Mg})$ & Titanium $(\mathrm{Ti})$ & Iron $(\mathrm{Fe})$ \\
Alloy & $\mathrm{Cu} 110$ & AA 6061-T6 & AZ31B & G2 CP Ti & 1018 \\
\hline
\end{tabular}

Table 1. Specific alloys used for these experiments. For ease of reading, alloys are referred to by their element symbols.

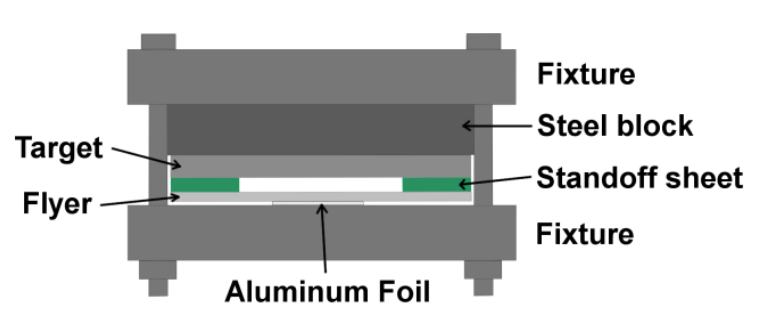

Figure 1. Apparatus used for collision welding.

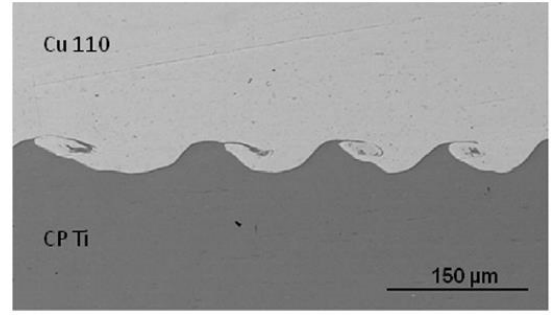

Figure 2. Exemplar wavy interface for a $\mathrm{Cu}$-Ti weld. 